\title{
CUTANEOUS MANIFESTATIONS OF SYSTEMIC LUPUS ERYTHEMATOSUS
}

\author{
NAHID PARVEEN ${ }^{1}$, DIPAK KUMAR DAS ${ }^{2}$, F.R.M. MAHBUBUL HAQUE ${ }^{3}$, MAHAMUDUN NABI \\ MOHAMMAD MOMTAZUL HAQUE ${ }^{4}$
}

\begin{abstract}
:
Systemic lupus erythematosus (LE) is a heterogeneous, multisystem, autoimmune disease characterized by the production of auto-antibodies against several cell constituents. The skin is one of the target organs most variably affected by the disease can be yield valuable diagnostic \& prognostic information. The present study was conducted to evaluate cutaneous manifestations of SLE in Bangladeshi patients. 100 cases of SLE were collected from the Department of Dermatology, BSMMU, Dhaka. The diagnosis was based on American Rheumatism Association Criteria. Cutaneous changes were recorded on a predevised pro forma. LE specific cutaneous changes noted were: Malar rash or butterfly rash (70.0\%), maculopapular rash (19.0\%), discoid rash (10.0\%), and bullous LE (10.0\%). Non specific LE lesions noted were: Photosensitivity (75.0\%), alopecia (47.0\%), oral mucosal lesion (34.0\%), hyperpigmentation (20.0\%), nail change (15.0\%), Raynauds phenomenon (12.0\%), Palmar erythema, genital lesion, periungual talangiectesia, leg ulcers, livedo reticularis, erythema multiform were rare. Systemic lupus erythematosus is a multisystem disease that predominantly affects women. Cutaneous lesions are the most important diagnostic tools as reflected by the fact that they account for four of the 11 revised American Rheumatism Association criteria of SLE. The pattern of skin changes may vary from place to place.
\end{abstract}

Key Words: SLE, LE specific and non specific cutaneous lesions

\section{Introduction:}

Systemic lupus erythematosus (SLE) is a heterogeneous, multisystem, autoimmune disease characterized by the production of auto-antibodies against several cell constituents. The skin is one of the target organs most variably affected by the disease. ${ }^{1,2}$ The prevalence of systemic lupus erythematosus (SLE) is $17-48 / 100,000$ population worldwide. $^{3}$

SLE is perhaps the best example of a multi system disorder in which cutaneous components of the disease can be yield valuable diagnostic \& prognostic information. Variations in environmental cultural or genetic factor may exist in the incidence, clinical heterogenecity and severity of disease between different ethnic and racial groups. ${ }^{2,4-6}$

The skin \& mucous membrane are symptomatically involved at some point in over $80.0 \%$ of patients with systemic lupus erythematosus. ${ }^{2,7}$ There is a tremendous variability and diversity in the type of involvement ranging from classical butterfly rash and atrophic hyperkeratotic lesions of discoid lupus to bullae, alopecia and vasculitis. ${ }^{2}$

Cutaneous lesions are account for four of the 11 revised American Rheumatology Association criteria of systemic lupus erythematosus: Malar rash, Discoid rash, Photosensitivity (skin), Oral ulcers (oral or nasopharyngeal, usually painless). ${ }^{1,2}$

Many studies conducted on abroad address the cutaneous manifestations in patients with SLE; however, scanty data are available on the topic among Bangladeshi origin. The present study was conducted to evaluate the cutaneous manifestations of SLE in Bangladeshi patients.

1. Medical officer, Department of Dermatology and Venereology, Bangabandhu Sheikh Mujib Medical University, Dhaka

2. Consultant, Department of Dermatology and Venereology, Bangabandhu Sheikh Mujib Medical University, Dhaka

3. Medical officer, Neuromedicine, Bangabandhu Sheikh Mujib Medical University ( BSMMU), Dhaka

4. Director, Salvation Hospital, Dhanmondi, Dhaka 
Cutaneous Manifestations of Systemic Lupus Erythematosus

\section{Material and methods:}

This cross sectional study was conducted at the department of Dermatology and Venerealogy, BSMMU, Dhaka from $1^{\text {st }}$ January 2007 to $31^{\text {st }}$ December 2007. Hundred patients of SLE (diagnosed on the basis of American Rheumatology Association criteria) were enrolled in the study. A detailed history and physical examination were recorded. The relevant biochemical and hematological profile were carried out.

Data was collected in a pre-design and pre-tested data collection sheet. Data were processed and analyzed using software SPSS-12 (Statistical Package for Social Sciences). Data processed on categorical scale were presented as frequency and percentage. While the data presented on continuous scale were presented as mean and SD. The summarized data were then presented in the table and chart.

\section{Results:}

We have assessed the cutaneous signs in 100 patients with systemic lupus erythematosus seen during one year period in BSSMU. All patients fulfilled the ARA criteria for SLE. 84\% patients of the present study group were female and $16 \%$ were male with male to female ratio of 1:5.25. Mean age of the patients was 30.04 years (9.12) with an age range from 15 to 54 years. $76.0 \%$ patients were married, $54.0 \%$ house wife. Maximum patients were from middle class family (50.0\%).Demographical variables of SLE patients are shown in Table I.

We classified cutaneous lesions as LE-specific (acute, subacute and chronic) and LE-non specific related, e.g. photosensitivity, Raynauds phenomenon, vasculitis, hair change and some others.
Table-I

Demographical variables of patients with SLE

\begin{tabular}{llc}
\hline $\begin{array}{l}\text { Demographic } \\
\text { variables }\end{array}$ & Character & Value \\
\hline Sex & Male: Female & $\begin{array}{c}1: 5.25(16.0 \% \\
\text { vs. 84.0\%) }\end{array}$ \\
Marital Status & Married & $76(76.0 \%)$ \\
& Unmarried & $23(23.0 \%)$ \\
& Others & $1(1.0 \%)$ \\
Occupation & House wife & $54(54.0 \%)$ \\
& Student & $21(21.0 \%)$ \\
& Service & $14(14.0 \%)$ \\
& Business & $5(5.0 \%)$ \\
Socioeconomic & Others & $6(6.0 \%)$ \\
condition & Upper & $10(10.0)$ \\
& Middle & $50(50.0)$ \\
Family history of & Power & $40(40.0)$ \\
SLE Age (year) & Meant \pm SD & $2(3.3 \%)$ \\
& Minimum & 15 \\
& Maximum & 54 \\
\hline
\end{tabular}

At the time of presentation only $15(15.0 \%)$ patients had only cutaneous lesions, 56 (56.0\%) patients had both cutaneous and systemic lesions and $29(29.0 \%)$ had only systemic lesions.

Acute cutaneous LE lesions included malar rash or butterfly rash seen in 70 patients $(70.0 \%)$, maculopapular rash seen in $19(19.0 \%)$ patients and bullous LE seen in $10(10.0 \%)$ patients.

Three patients (3.0\%) had psoriasiform subacute cutaneous lesion. Chronic cutaneous LE lesion was: 10 patients had chronic discoid lesions (DLE), $6(6.0 \%)$ had hypertrophic or lupus DLE and 5 (5.0\%) had lupus profundus.

Table-II

Frequency of different $L E$-specific lesions in patients of SLE

LE-specific lesions

\begin{tabular}{lll} 
Category & Skin lesions & $\mathrm{n}(\%)$ \\
\hline Chronic cutaneous LE & Discoid rash & $10(10.0)$ \\
& Hypertrophic or lupus DLE & $5(5.0)$ \\
Subacute LE & Lupus profundus or Lupus erythematosus panniculitis & $5(5.0)$ \\
Acute LE & Psoriasiform lesions of subacute LE & $3(3.0)$ \\
& Malar rash or butterfly rash & $70(70.0)$ \\
& Maculopapular rash & $19(19.0)$ \\
& Bullous LE & $10(10.0)$ \\
\hline
\end{tabular}


Non specific lesion of SLE included photosensitivity (75.0\%), Raynauds phenomenon (12.0\%), live do reticularis $(3.0 \%)$, leg ulcers $(4.0 \%)$, periungual talangiectesia (5.0\%), palmar erythema $(7.0 \%)$ and erythema multiform (1.0\%). Hyperpigmentation occurred in $20.0 \%$ of patients. Hair changes included (Fig.-1) alopecia (47.0\%) among them scarring (5.0\%) and non scarring (42.0\%).

\section{Table-III}

Frequency of different LE-nonspecific lesions in patients with SLE

\begin{tabular}{lc}
\hline Non-specific LE-lesions & $\mathrm{n}(\%)$ \\
\hline Photosensitivity & $75(75.0)$ \\
Alopecia & $47(47.0)$ \\
Oral mucosal lesion & $34(34.0)$ \\
Hyperpigmentation & $20(20.0)$ \\
Palmar erythema & $7(7.0)$ \\
Nail change & $15(15.0)$ \\
Raynauds phenomenon & $12(12.0)$ \\
Genital lesion & $5(5.0$ \\
Periungual talangiectesia & $5(5.0)$ \\
Leg ulcers & $4(4.0)$ \\
Livedo reticularis & $3(3.0)$ \\
Erythema multiform & $1(1.0)$ \\
\hline
\end{tabular}

Oral mucosal lesions and genital mucosal lesions occurred in $34.0 \%$ and $5.0 \%$ of the patients respectively. Oral lesions were noted on lips (9.0\%), palate $(9.0 \%)$, and buccal mucosa $(16.0 \%)$. The rest of the mucosal surfaces of the body were not affected. Fifteen patients presented with nail changes. The frequency of LE-specific lesions and LE-nonspecific lesions is shown in Table II and III.

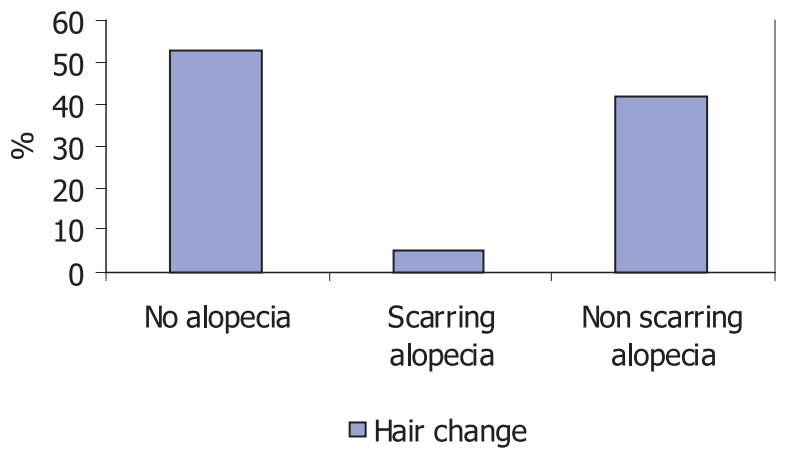

Fig.-1 : Bar diagram of different types of hair changes

\section{Discussion:}

The skin findings seen in lupus erythematosus can present with either lupus-specific or lupus-nonspecific findings, with lupus-specific skin disease showing findings histopathologically distinct for cutaneous lupus erythematosus. Lupus-specific skin diseases include chronic cutaneous, subacute cutaneous, and acute cutaneous lupus erythematosus. The types of skin lesions in each group are clinically distinct and recognizing the specific subsets helps in prognosticating the likelihood of underlying systemic lupus. Lupus nonspecific skin lesions are not histopathologically distinct for cutaneous lupus and/ or may be seen as a feature of another disease process. ${ }^{8}$ Nonspecific disease-related skin lesions are telangiectasia, dermal vasculitis, rheumatoid nodules live do reticularis, alopecia, urticaria, photosensitivity, Raynauds phenomenon, oral mucosal lesion, leg ulcers etc. ${ }^{1,9}$

High prevalence and diverse spectrum of cutaneous changes in SLE patients were noted from our study that is comparable with the findings of some other studies by Rabbani et al. ${ }^{2}$, Yell et $\mathrm{al}^{9}$ and Cardinali et al. ${ }^{10}$ Cutaneous manifestations were initial presentation in $15.0 \%$ of our patients as against $25.0 \%$ mentioned by Watson ${ }^{11}$ and Kapadia ${ }^{12}$ and $10.0 \%$ by Rabbani ${ }^{2}$. Female dominant picture of our study was closely matched with other study (e.g. 28 out of 32 in an Indian study conducted by George et al ${ }^{13}, 73$ out of 78 in an Austratian study by Weinstein et $\mathrm{al}^{14}$ and 172 out of 196 in an Pakistani study conducted by Rabbani et $\mathrm{al}^{2}$ ). Mean age of the patients was correlated with Rabbani et al (31 12.3$){ }^{2}$

Malar rash was the most common LE specific finding of our study. This is in accordance with the previous reports. ${ }^{15-18}$ But differ from Patal et al $(40.0 \%)^{3}$ and Rabbani et al (31.0\%) $)^{2}$ and Cervera et al $(31.1 \%)^{19}$. Among the LE-specific lesions, percentage of discoid rash was lower than that recorded by Rabbani et $\mathrm{al}^{2}$ (10.0\% vs. $15.0 \%$ ). Bullous LE and maculopapular eruption was reported higher in present study than described by Cardinal et al. ${ }^{10}$ They found only one cases among 186 patients had bullous LE and one had maculopapular eruption.

Three patients of our study had psoriasiform subacute LE lesion where as $5(7.0 \%)$ patients had in another study conducted by Yell et al and $6.7 \%$ by Muzaffar et al. ${ }^{18}$ 
Photosensitivity was more common LE nonspecific findings of present study (75.0\%) but widely differ from Rabbani et $\mathrm{al}^{2}(33.0 \%)$, Saurit et $\mathrm{al}^{20}(57.1 \%)$ and Muzaffar et $\mathrm{al}^{18}$ (53.3\%).

Hyperpigmentation was noted $20 \%$ of our study which is consonance with Rabbani et $\mathrm{al}^{2}$ but differ from Tuffanelli et $\mathrm{al}^{21}$ where they note it is $8.4 \%$. This difference could be due to excessive exposure to sunlight in our subcontinent and a general tendency to post inflammatory melanosis.

Non scarring alopecia was a frequent finding of our study (seen in $42 \%$ of our patients) as compared to $37.0 \%$ quoted by Akhtar and khan, ${ }^{22} 22.0 \%$ by Rabbani, ${ }^{2} 57.0 \%$ by Wysenbeek ${ }^{23}$ and $58.0 \%$ by Alarconsegovia ${ }^{24}, 31.0 \%$ by cardinali ${ }^{10}$ and $40.0 \%$ by Yell et al. Rothfield, ${ }^{24}$ however, noted this sign in $70.0 \%$ of his patients.

Oral mucosal lesion were observed more in our study than some other studies ${ }^{2,3,20}$ Raynauds phenomenon was observed $12.0 \%$ in our study. It is nearly correlated with Cervera et al's ${ }^{19}$ findings but much less than from some others findings. ${ }^{9,20}$

Palmar erythema, genital lesion, periungual talangiectesia, leg ulcers, livedo reticularis, and erythema multiform were also noted on varying scale of our study.

\section{Conclusion:}

Systemic lupus erythematosus is a multisystem disease that predominantly affects women. Cutaneous lesions in SLE are important as a diagnostic aid as reflected by the fact that they account for four of the 11 revised American Rheumatism Association criteria of SLE. The pattern of skin changes may vary from place to place.

\section{References:}

1. Berbert AKCV, Mantese SAO. Cutaneous lupus erythematosus - Clinical and laboratory aspects. An Bras Dermatol 2005; 80:119-31

2. Rabbani MA, Shah SMA, Ahmed A. Cutaenous manifestations of Systemic lupus erythematosus in Pakistani Patients. J Pak Med Assoc 2003; 53: 539-41.

3. Patel P; Werth V, Cutaneous lupus erythematosus: a review. Dermatol Clin 2002; 20: 373-85
4. Hochberg MC, Boyd RE, Ahearn JM. Systemic lupus erythematosus: A review of clinico-laboratory features and immunogenetic markers in 150 patients with emphasis on demographic subsets. Medicine (Baltimore) 1985; 64: 285-95.

5. Font J, Bosch X, Ingelmo M. Acquired ichthyosis in a patient with SLE. Arch Dermatol 1990; 126-9.

6. Tan EM, Cohen AS, Fries JF. The 1982 revised criteria for classification of SLE. Arthritis Rheum 1982; 25: 1271-7.

7. McCauliffe DP. Cutaneous lupus erythematosus. Semin Cutan Med Surg 2001; 20: 14-26.

8. Werth VP. Clinical manifestations of cutaneous lupus erythematosus. Autoimmun Rev 2005; 4: 296302.

9. Yell JA, Mbuagbaw J, Burge SM. Cutaneous manifestations of systemic lupus erythematosus. Br. J dermatol 1996; 135: 355-62

10. Cardinali C, Caproni M, Bernacchi E, Amato L, Fabbri P. The specturm of cutaneous manifestations in lupus erythematosus- the Italian experience. Lupus 2000; 9: 417-23.

11. Watson R. Cutaneous lesions in SLE. Med Clin North Am 1989;73:1091-1109.

12. Kapadia N, Haroon TA. Cutaneous manifestations of systemic lupus erythematosus. Int J Dermatol 1996; 408-9.

13. George R, Mathai R, Kurain S. Cutaneous lupus erythematosus in India. Immunoflouresence profile. Int J Dermatol 1992; 31: 265-8.

14. Weinstein C, Miller MH, Axtens R. Livido reticularis associated with increased titres of anti cardiolipin antibodies in SLE. Arch Dermatol 1987; 123: 596-600.

15. Silverman ED, Eddy A. Systemic lupus erythematosus: a comparison of onset, clinical features, serology and outcome. Br J Rheumatol 1995; 34: 866-72

16. Font J, Cervera R, Espinosa G. Systemic lupus erythematosus (SLE) in childhood: analysis of clinical and immunologic findings in 34 patients and comparison with SLE characteristics in adults. Ann Rheum Dis 1998; 58: 456-9. 
17. Rood MJ, Cate R, Smith LW. Childhood-onset SLE: clinical presentation and prognosis in 31 patients. Scand J Rheumatol 1999; 28: 222-6.

18. Muzaffar F. Cutaneous manifestations of systemic lupus erythematosus in Pakistani children. Journal of Pakistan Association of Dermatology 2004; 14: 110-3.

19. Cervera R, Khamashta MA, Font J, Sebastiani GD, Gil A, Lavilla P et al. Morbidity and mortality in systemic lupus erythematosus during a 10-year period: a comparison of early and late manifestations in a cohort of 1,000 patients. Medicine (Baltimore) 2003; 82: 299-308.
20. Saurit V, Campana R, Ruiz LA, Ducasse C, Bertoli A, Aguero S et al. Mucocutaneous lesions in patients with systemic lupus erythematosus. Medicina (B Aires) 2003; 63: 283-7

21. Tuffanelli DL, Dubois EL. Cutaneous manifestations of SLE. Arch Dermatol 1964; 90: 377-86.

22. Akhter J, Khan MA. SLE in Pakistan. Specialist 1992; 9:25-7.

23. Wysenbeek AJ, Leibovici L, Amit M. Alopesia in SLE. J Rheumatol 1991; 18:1185-6.

24. Rothfield NF. SLE clinical aspects and treatment. In: McCarty DJ, ed. Arthritis and allied conditions. Philadelphia: W.B. Saunders, 1990: 183-6. 